This is an electronic reprint of the original article. This reprint may differ from the original in pagination and typographic detail.

Author(s): Maunula, Minna; Isosomppi, Leena

Title: Developing Web-based Academic Adult Education: Learning Experiences as Starting Points for Planning and for Continuous Development

Year: $\quad 2015$

Version:

Please cite the original version:

Maunula, M., \& Isosomppi, L. (2015). Developing Web-based Academic Adult Education: Learning Experiences as Starting Points for Planning and for Continuous Development. The International Journal of Interdisciplinary Educational Studies, 10(2), 27-37. https://doi.org/10.18848/2327-011x/cgp/v10i02/59378

All material supplied via JYX is protected by copyright and other intellectual property rights, and duplication or sale of all or part of any of the repository collections is not permitted, except that material may be duplicated by you for your research use or educational purposes in electronic or print form. You must obtain permission for any other use. Electronic or print copies may not be offered, whether for sale or otherwise to anyone who is not an authorised user. 


\section{CHANGE NOTE}

Please list the changes you have made to your paper as a result of reviewer comments and feedback. In some circumstances we may return this change note to reviewers.

\section{Reviewer Number 1}

\section{Changes Made as a Consequence of Comments and Suggestions}

1.

2.

Suggestions Rejected, With Reasons for Rejection

1.

2.

\section{Reviewer Number 2}

\section{Changes Made as a Consequence of Comments and Suggestions}

1. "The area of research is of importance to the wider audience and is timely. The literature references at the moment is thin and more literature needs to be utilized."

- More relevant literature is added: (here without doi numbers)

Cervero, Ronald, M., and Arthur, L. Wilson. 2001. "At the Heart of Practice. The Struggle for Knowledge and Power." In Power in Practice: Adult Education and Struggle for Knowledge and Power, edited by Ronald M. Cervero, and Arthur L. Wilson, 1-20. San Fransisco: Jossey-Bass.

Hara, Noriko, and Rob Kling. 2000. "Student Distress in Web-based Distance Education Course." Information, Communication and Society 3(4):557-79.

Huang, Hsiu-Mei. 2002. "Toward Constructivism for Adult Learners in Online Learning Environments." British Journal of Educational Technology 33(1):27-37.

Hämäläinen, Raija, and Katja Vähäsantanen. 2011. "Theoretical and Pedagogical Perspectives on Orchestrating Creativity and Collaborative Learning." Educational Research Review 6:169-84.

Maor, Dorit. 2003. "The Teacher's Role in Developing Interaction and Reflection in an Online Learning Community." Educational Media International 40(1-2):127-37.

Molesworth, Mike, Elizabeth Nixon, and Richard Scullion. 2009. "Having, Being and Higher Education: The Marketisation of the University and the Transformation of the Student into Consumer." Teaching in Higher Education 14(3):277-87. 
Rubenson, Kjell, and Richard Desjardins. 2009. "The Impact of Welfare State Regimes on Barriers to

Participate in Adult Education. A Bounded Agency Model." Adult Education Quarterly 59(3):187-207.

Wallace, Raven, M. 2003. "Online Learning in Higher Education: A Review of Research in Interaction among Teachers and Students." Education, Communication \& Information 3(2):241-80.

2. "The conclusion section does not engage adequately with the review literature and the "so what" question."

- Conclusion section has been rewritten and discussion "so what" question in Conclusion has been deepened.

3. "The relevance to the practice and academia needs to be made more explicit in the concluding section of the paper."

- The relevance to the practice and academia is discussed in Conclusion more focused than it was done in the previous article version.

Suggestions Rejected, With Reasons for Rejection

1. "Does not engage much with theory except for literature references. The theoretical contribution could improve the paper."

We find this feedback valuable for our further study. In this article we are aiming to describe and to reflect an e-pedagogical case story and both adult students' and our own learning experiences as teachers. We make an effort to outline the academic web-based adult education phenomenon and its societal and pedagogical starting points in a problem-based way. There is a theoretical outline of web-based academic adult education in a societal context in the beginning of the article, and some references to learning theories later.

2. "Some good interview quotes are provided but in-depth discussion is lacking. The article needs to employ more interview data and have in depth discussion of the interviews. "

- Students' written feedback material has been utilized in the article. The authors' / teachers' reflective discussions are another part of the empirical information and that reflection is written widely in the article, (see article page 2: "We describe and evaluate the functionality of the pedagogical manuscript and the areas of development of the two partly different study modules on the basis of the written student feedback material and our own reflections on the teaching experiences.") - Also the teachers' reflection and professional learning experiences are in important role in the developing process. Communal reflections on the teachers' own professional experiences can be found widely in the text. 


\title{
Developing web-based academic adult education - learning experiences as starting points for planning and for continuous development
}

\author{
Maunula Minna, University of Jyväskylä, Kokkola University Consortium Chydenius, Finland
} Isosomppi Leena, University of Jyväskylä, Kokkola University Consortium Chydenius, Finland

\begin{abstract}
Different innovative web-based solutions have made wide-ranging global breakthroughs. Increasingly flexible initiatives are expected in the future from web-based solutions also in education and in developing expertise. Global changes reach individuals in their everyday life and web-based education enables the realization of lifelong learning in many ways. Traditionally, academic adult students' most central challenge has been the practical difficulties in participation: many connecting factors and responsibilities overlap in busy everyday lives. The new web-based teaching solutions have enabled participation in academic studies more equally and for an increasingly wider group. In practice, the development continues proceeding as a process of different experiments, mistakes and insights. In this article we present, with regard to pedagogical candidate level research methodology studies in Finland, the development of webbased studying and teaching, adult students' experiences and evaluation of their own learning and the experiences of teachers regarding challenges and future views of web-based teaching. Especially in web-based academic adult education the significance of the planning stage and web-based pedagogical and adult educational starting points are emphasized: flexibility, independence of time and place, intelligibility of high quality expert teaching and wider recognition of starting points of adult students.
\end{abstract}

Keywords: web-based learning, academic adult education

\section{Academic adult education at the intersection of social equality, the education market and science foundation}

$\mathrm{G}$ lobal technological, economic and social development requires the adults who struggle under the pressure of education and labour market to regularly update their knowledge and to learn new things. From the point of view of the education market, updating knowledge at the individual level maintains personal competitive ability and for its part also increases the meaningfulness of work and the controllability of the change (Molesworth, Nixon, and Scullion 2009). The increasing expert tasks in the working life in turn require the education systems to offer university level education and degree studies. University level adult education in Finland is arranged mainly as open university studies, continuing education and especially through a few conversion education and Master's degree programmes that have been aimed at adults. However, it is often demanding to adapt these studies to the adults' situations in life and to different starting points. Simultaneous individual, social and global preconditions set expectations, objectives and restrictions for the academic adult education. In the education market, academic adult education has become a commodity and capital to be purchased but when examined socio-politically the academic adult education should not only promote competitive ability but also more broadly the social equality and the strategy for lifelong learning (Cervero and Wilson 2001). These starting points that are sometimes laden with tensions become concrete in the operation of the open university when adults from different social and educational starting points make education choices based on accessibility and student centeredness. Furthermore, the promotion of scientific education and educating in the practices of scientific community are connected to the task of academic adult education, this is emphasized in particular in the study modules of the academic education which are related to research, bringing their own challenges for learning and teaching. 


\section{Web-based learning as a solution for academic adult education}

High expectations are directed globally at adapting educational technology and web-based education in regard to lifelong learning and increasing equality. Web-based education, having grown during the last few decades, has indeed opened new opportunities for the attainment of the objectives of lifelong learning. However, the promise of the equality given by the technology has not become unambiguously fulfilled according to international studies (Selwyn, Gorard, and Furlong 2006). It is indeed important to analyse the social effects of technological solutions and to also critically examine it in the contexts of adult education.

A number of phenomena of the current time culminate in web-based academic adult education: demand for high-quality knowledge and skills, constant updating of knowledge and emphasis on individuality in many different ways (Beck and Beck-Gernsheim 2002). One of the challenges of adult education is time, obvious difficulties in the use of time and, on the whole, a changed attitude to time. Time must be controlled and the little time available must be used wisely (Rubenson and Desjardins 2009, 191; Southerton 2011). The many dimensions of the use of time appear particularly clearly when the academic adult students' everyday life is examined (Maunula 2014a; Maunula 2014b). Even though in the 2000s the new learning environments which utilize the technology have expanded, the full-scale utilization of their possibilities in the academic adult education is rather at an early stage.

\section{E-pedagogical case story: Research methods in open university}

In this article, we describe first the recent history of the pedagogical development of the webbased teaching and learning that has been carried out in our own department. Then we relate our own pedagogical case story of the study module in qualitative research methods (5 study credits). This course, which is part of the bachelor level studies, was carried out during the two study years in the open university, partly in different ways by different teachers, which gives the opportunity to compare different forms of implementation and pedagogical solutions related to them. Both writers have acted as the teachers of the study module. We describe and evaluate the functionality of the pedagogical manuscript and the areas of development of the two partly different study modules on the basis of the written student feedback material and our reflections on the teaching experiences. Finally we outline the future outlook for the web-based teaching of methodology.

\section{Continuous development of web-based teaching}

The different flexible web-based teaching solutions have already been at least in partial teaching use for several years at our university centre. During the last few years the ubiquitous learning environment has been developed (e.g. Hakala and Myllymäki 2013), in which e-learning and recorded materials, ease of participation in the teaching and paying attention to everyday starting points of the students have been at the center of the development. The needs for development have arisen from the practice and the objective has been to develop educational practices based on research and for the needs of adults students. The feedback and development ideas from the students have played a central part in this development.

The open university education at the university centre has also already been developed towards web-based education and e-pedagogically meaningful solutions for many years. Before a gradual technological turn, teaching of the research methods was also carried out as traditional lectures to attend to, which required travelling to the teaching locality for many of the students. Later on the lectures were transmitted online in real time, closer to the students to the different cooperation localities of the open university where the adult students met together with a tutor to attend. In this way the students avoided travelling, saved time and money and also the education was within reach of a wider group. In the following phase of development the lectures were saved for a limited period and the students were able to follow them virtually on their own 
computer. However, the lecture teaching was directed at the attendees and attention was not really paid to the virtual participants, for example, there was no interaction in addition to the livechat. Also the possible teaching materials were delivered with delay.

After this the teaching has been transferred online more widely and it has been more pedagogically thought out. The accessibility of the education has improved but the challenges of web-based teaching and learning require further pedagogical consideration. In the web-based education of the open university the principles of the trialogical model of learning (Paavola and Hakkarainen 2009) are employed and the ubiquitous learning environment is sought after, which both emphasize the dialogical nature of adult student's already existing knowledge, the everyday operational contexts and the new educational contents.

\section{Two web-based implementations of the study module in qualitative research methods}

The altered conception of time, the understanding of the relative nature of scientific information and the versatile online possibilities offer plenty of areas of development for the teachers of research methods. In the following, we examine adult pedagogical hubs which have arisen in the implementation and development of the study module in qualitative research methods.

The pedagogical challenges in this study module rose from the heterogeneity of the students' educational backgrounds but also from the nature of the material to be studied. Students who are both at the beginning of their first studies on research methods and those with a Master's background, as well as even the postgraduate students from a parallel discipline, study in the open university's study groups. The challenge of teaching the qualitative research methods as part of the academic adult education is increased by the requirement of scientific thinking and the general academic expert skills such as scientific argumentation, science-based thinking and analysing the concept of scientific knowledge itself.

\section{Dividing teaching and supervision into sections}

Teaching and supervision in qualitative research methods (30 h) was carried out at both times of implementation in the Adobe Connect (AC) and Optima web-based environments. There were two student groups: 32 students the first time and 40 for the second. For the first time, the lectures and supervision were in real-time, and simultaneously as recorded evening lectures and supervision sessions within 3-4 weeks. Adult students could in this way choose either real-time participation or viewing the recorded material. Teaching was packaged in five lesson periods which contained both lectures and the students' interactive considerations and tasks in small groups. The evening lectures made participation possible but the scheduling proved to be heavy for the last sessions and for the consecutive evenings of the lengthy period both to the students and to the teacher.

The second time, teaching was as lectures in short 20-60 minute video and audio recordings in the Adobe Connect web-based environment. The recorded lecture proceeded according to the nature of the qualitative study process and they were published regularly every week. Splitting contents into smaller parts promoted the opportunity for learning with understanding, according to the students' experiences.

The interactive part was carried out this time as separate teacher's supervision sessions lasting about an hour, which could be participated in 'live' virtually or followed as a recorded sessions later on according to choice. Lightening the schedule and organizing the contents into separate, shorter parts helped some of the students who follow video recordings to pace their participation meaningfully from the learning point of view. According to the adult students' feedback the lecture type web-based teaching must be faster paced, expert in content and well organized. The adult students wanted to have exact schedules, high-quality material beforehand and on the whole they tried to maximize the effectiveness of their use of time. Lecture sessions 
lasting several hours, which proceed as the teacher's loose narration and without the advance information of the sequence of contents are challenging for busy adults, in particular when followed as web-based recordings. The adult students were satisfied as a rule when they could participate virtually in the education and at a convenient time for themselves. The clear structure of the course and the clear appearance facilitated grasping the subject which was experienced as fairly difficult in content and pacing the learning process. A prior schedule was drawn up for teaching and supervision, with the purpose of bringing pace and shape to the study. However, the students experienced the given schedules individually: others found them helpful in progressing through the process, others were beleaguered by them and felt hurried in studying. At the planning stage of the study module there was an awareness of different adult students' time commitments and an attempt was made to pay attention to them by making self-directed progress possible.

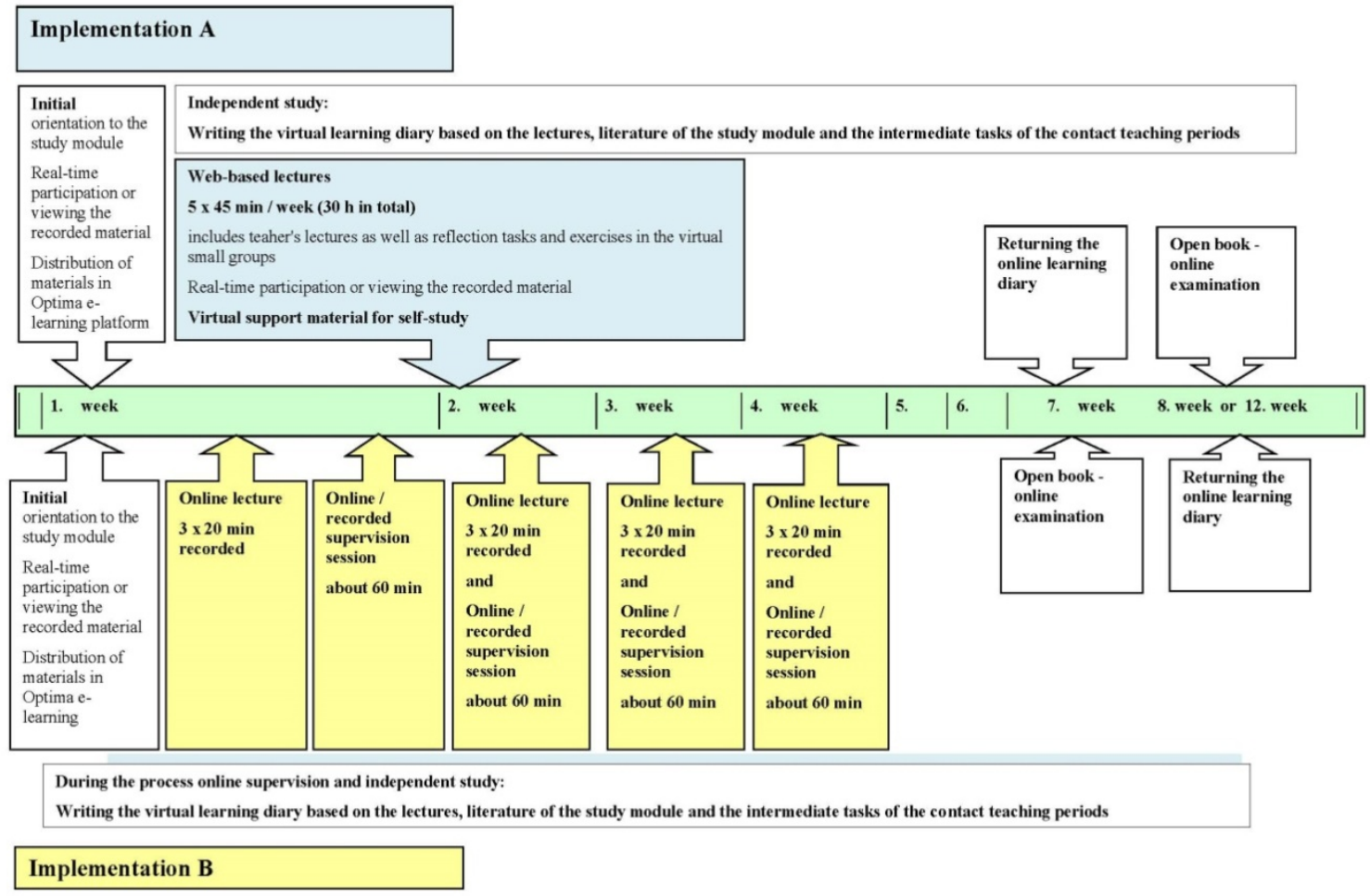

Figure 1: The progress of the study module on qualitative research methods.

\section{Significance of the initial orientation}

To begin both the study modules the teacher gave a short online supervision session about the study module in which the students were allowed to participate synchronously online or to view recorded material later according to their own choice. The first supervision time was important to the parties: the teacher encouraged participation in the supervision and drawing up of such aims for the study module and for the smaller tasks that each adult student could genuinely learn and challenge themselves. From the students' point of view, meeting the teacher and the other 
students online created an experience of community and lowered the threshold of requesting supervision during the study module. When working online, students want real personal contact (Hara and Kling 2000; Persell 2004; Wang 2009). Already the information about an accessible person inspired confidence. The e-learning platform was also used for asymmetric interaction during the study module. In addition to the materials to be distributed, it also contained a virtual discussion area which was utilized in communication and sharing information in the study module. The students gave good feedback on the supervision relating to the beginning of the study module and on the individual student study supervision during the study module.

\section{Virtual interaction}

In the first implementation, the video lectures contained the teacher's lecturing and small group discussion in the virtual small group space. The discussions were based on the short reflection tasks presented by the teacher and on longer (about 30-45 min.) cooperative exercises. These small group discussions were not videoed but the teacher could visit the virtual group spaces and participate in the discussion of the group. However, the groups presented their own tasks and results of their discussion in the shared virtual space so the students who viewed recorded lectures were able to follow the teacher's and the students' discussion for these parts. Students were able to decide whether to participate in real-time in the teaching or to view the video recordings later. The majority of the students chose working independently and watching the recorded lectures afterwards.

In the second time of implementation there was separate web-based supervision for studying and the contents of the study module were available for the students in addition to the lecture recordings. The supervision was available online in real time and these supervision sessions were also recorded. The supervision questions presented during the study module were connected to contents or to completing the course. The web-based interaction connected to the study contents was regarded as significant even though the threshold for posing questions in the supervision situation which was to be recorded was regarded as high. The students were nervous about speaking, particularly about recording their own questions to be seen and heard by the other participants.

The participation of a few students enlivened and also supported the viewers of the recorded sessions in analysing the contents. It was seen in the student feedback how following an interactive discussion and the questions posed by other students had helped their own learning (see Wang 2009, 10). It was easy to identify with another student and the discussion that had taken place was experienced as significant for learning even when viewed as recorded material. Many of the students were also sorry that they had not found time for real-time discussion about study content. From the point of view of the teacher and the fellow students, the commitment of a few students to the real-time interaction was an extremely important factor which deepened the demanding contents naturally. An adult student who participated in a web-based study module for the first time describes this experience as follows:

The students participating through the web created a feeling as if you were one of them. The more questions the web-students asked, the better. The questions were exactly the ones that I was also thinking about. (---) As I viewed the video recordings afterwards, I did not get answers to many of my questions. When completing tasks in particular, you sometimes feel quite lost. If I got only little sidetracked from the subject in the livesituation, the teacher or the students would be able to direct me to the right track. There is no possibility for this now and I think it is really bad. (Student A12)

From the point of view of the freedom of self-study and anticipated effectiveness as well as learning, the relation of meaningful interaction in studying proved sometimes to induce tension from the student's point. Some of the students indeed re-evaluated their choice of the form of 
studying after the experience.

In some ways the compulsory communication with the others and at the same time the teacher's (perhaps only once) feedback would be appropriate. (Student A15)

Learning was made more difficult by my own decision to study independently. It is worth taking part in the web-based lectures. (Student A16)

I would absolutely like to know if I have learned the matters correctly. I mean before the examination. When I completed tasks, for example, I did not know if I had understood the matters correctly. (Student A14)

The students who viewed recorded materials afterwards at the second time of implementation had a different experience of the significance of interaction. Virtual interaction was minor as a whole and it concentrated mainly on the weekly supervisory meetings. In the teacher-led shared supervision sessions to be recorded the interaction did not stretch to be the students' shared analytical discussion and the dialogue was of a question-and-answer type between the teacher and the students. As one of the students put it: "Because I was not in contact with the students and the lecturer during the teaching, I have not experienced a concrete sense of community in this context. At this stage it seems to me that I have to go alone on this road to be able to study at my own pace.” (Student B1.)

Based on the feedback material, it is still good to offer and to develop different ways of participation (see Makkonen 2003; Persell 2004). In web-based teaching, the anonymous participation in the interactive situations should indeed be made possible better than before. On the other hand, the anonymity increases the feeling of distance and may also partly disturb interaction.

\section{Supporting the learning process with a learning diary, intermediate tasks and support materials}

In addition to viewing the lectures, the completion of the study module required the student to write an online learning diary on a separate e-learning platform. This element was inherited from an earlier study module and proved to be a valuable tool for documenting the learning process. The diary had to contain consideration for the lecture themes and exercises which comply with the stages of the qualitative research process as well as the student's reflection on their own learning. When a student wrote the learning diary regularly on the e-learning platform, the teacher could virtually follow the students' learning process, for example, the understanding of concepts. It was also possible to reflect on the teaching content to be recapped or further explored from the student's writing (see Persell 2004). The tight teaching schedule and, on the other hand, the freedom that was offered to the students concerning their own scheduling disturbed the fullscale utilization of this possibility that promotes asynchronous interaction in the teaching. For the students, writing was both a challenge and an element which deepened learning and made it visible.

The learning diary was an efficient tool for opening the concepts for myself. (Student A2)

The study diary was very multiform and required much work but at the same time it was also extremely educational. (Student B2)

Without the practical tasks the contribution would have been smaller. Now the matter had to be understood and applied by oneself. (Student B3) 
According to the students, the exercises that were carried out during the study module made concrete the stages of the study process. The meaningfulness of the tasks was increased by a possibility to connect them to a planned small-scale study, the planned contents and the methods of carrying out the research. Many of the students indeed aimed at utilizing the method studies in the seminar work in pedagogics. Also the possibility of choosing the contents of tasks increased their meaningfulness.

The written materials and video recordings of the study module were distributed to the students through the e-learning platform. Literature to be examined, in particular the handbooklike source on methods (Patton 2002) in English was challenging for a large portion of the students. Because of this there was also virtual support material available for the students at the first time of implementation. It was often regarded as useful as the next quotation shows: "The hints to the supplementary material were extremely comprehensive and it seems that acquiring them has been made extremely easy for the students” (Student A15).

The students reflected on their whole learning process in the last exercise of the learning diary. Reflection also on the virtual examination as a part of the learning process was made possible when the learning diary was returned after the examination.

\section{Open book - applied virtual examination}

The intensive duration of the study module was about one month, a period for which the teaching recordings and the web-based supervision had been scheduled. After the lecture recordings, webbased supervision, practice tasks and writing the learning diary, the students participated in the online examination from their home computers. The students could take the examination from their home computer during a certain examination period. The examination was so called open book -examination, in which the study material, in other words, the methodology literature to be examined and the lecture notes were allowed to be present and the tasks were applied exercises. The examination which evaluated understanding of the methodological concepts and principles, perception of the study process and the ability to read the scientific research reports with understanding, together with its applied tasks, was at its best regarded as a learning situation which deepened and collated what had already been learned: "Also the examination as a whole aided understanding” (Student A4).

\section{Technological learning and teaching environment}

The technological learning environment of the web-based teaching was comprised of technical equipment (in this case Adobe Connect real-time video and audio connection and Optima elearning platform) and of the teachers' and the students' e-learning backgrounds of experience and from the technical support available. Good knowledge of the technological equipment to be used and foresight relating to the technology are central in the planning of the study module from the point of view of the success of web-based education. As we teachers, many of the students in the open university already had experience in operating in these web-based environments. However, the introduction of new features in the teaching (for example, the virtual small group space) in addition to the basic use of familiar environments required some practice from the teacher and also produced technical surprises, such as difficulties for the students in accessing the video recordings.

\section{After pedagogical reflection}

\section{Teacher's role in the web-based education}

In web-based teaching the teacher's role is significant (Huang 2002; Maor 2003; Wallace 2003). The teacher is often both the expert of the contents of the field and the writer of the e- 
pedagogical manuscript, the supervisor of learning and the inventor of technical solutions for elearning (Hämäläinen and Vähäsantanen 2011). The teachers' attitude to the web-based teaching and to developing one's own teaching is central. In comparison to the traditional lecturing which takes place in the classroom, the cyclical stages of planning and developing are strongly emphasized in the web-based teaching.

In the beginning of the education, realizing the different starting points of the students and the teacher's meta speech about studying, teaching and of the different starting points of the adult students' studying are significant. In this way the teacher brings out the fact that the adult students' diversity, different everyday commitments and needs are recognized. Also different emotions were connected to the adult student's learning process, the experience of becoming accepted and the understanding attitude which was conveyed by the teacher brought calmness and confidence to the learning process according to the students' experiences (see Dirkx 2008; Hara and Kling 2000; Huang 2002; Zembylas 2008). The significance of the teacher as an encourager and a supporter of the learning could encourage the adults to critically reflect, to think about their own starting points, their objectives and on the whole to deepen the meaningfulness of the subject to be studied. The web-based teaching of the qualitative research methods in question had been designed to be rather student centered according to the students' evaluations.

The traditional lecture teaching cannot be moved online as such but it must be designed to a new pedagogical model as a whole. According to our earlier experience (Isosomppi and Maunula 2014), multiform web-based teaching where the students can participate live as face-toface and/or virtually online in real time is challenging for the teacher and dissipates concentration of all the participants. Because of this it is justifiable in some cases to maintain the teaching just as web-based or as traditional teaching. From the point of view of participant friendliness it would be desirable for the recorded teaching to be fluent and pleasant to view. It is an advantage for the teacher to gain personal experiences of participation from different web-based situations which can be mirrored in one's own web-based teaching. Of course, the lecture recordings can be edited and indeed that is partly done but it is not the most efficient way of action time-wise or economically.

\section{Meaningfulness of the contents}

Experienced meaningfulness of the subject which is studied and examined through research promotes the commitment to it (also Donovan, Green, and Mason 2014; Leonard, Becker, and Coate 2005). The teacher becoming conscious of the different starting points of the participants, objectives and already existing knowledge can be challenging in web-based teaching. The knowledge relating to research was far removed from the adult students' everyday experiences and a genuine surface of contact with the subject was a thin one. Optionality in regard to methods of studying and, on the other hand, possibility to connect the matters to be studied to the learner's own experiences were important adult pedagogical starting points in the planning and implementation of also this study module. The idea of trialogical learning (Paavola and Hakkarainen 2009) according to which the contents to be learned have genuine connections to the reality and the utility value, is important in particular in the adult education where it is expected that the expertise and the knowledge and skills are expressed in the genuine operational contexts.

In web-based teaching the different applied tasks which enable the adult students' individuality were also an essential part of teaching the research methods. For example, the task assignments which directed the students to think for themselves made making choices of contents possible for the students, so that the contents would be genuine and useful from the adult students' point of view. The multidisciplinary approach and its appreciation, even though the teacher could not master all the themes to be processed, was and should be even more strongly an objective - the problems of the expert contexts are not restricted to only one field of knowledge and the solutions can be creative and diverse (Billett 2001). 
The majority of the students who gave feedback experienced that they had learned the contents of the study module, in other words, the research process and gained more courage both in regard to contents and in e-learning. However, we neither have the reflections of the students who had discontinued the study module nor the exact number of them, which according to a rough estimate is about $20 \%$, for our use. Perhaps their possibly critical analyses would bring new valuable dimensions to evaluation, planning and development of the teaching. On the other hand, there was also criticism and development proposals in the reflections of the students who had completed the study module, in other words, the feedback information was versatile in content. When reading and evaluating the learning diaries and examination answers, the image of multi-levelled learning processes became concrete.

\section{The pedagogical interaction binds and intensifies feedback and learning}

Some of the students were satisfied with as independent a way as possible to study, some wished for more interaction to support learning in their feedback. From the teacher's point of view the lesser interaction was an e-pedagogical challenge. When interaction diminishes, the teacher's uncertainty about the possible grey areas of the subject matter, clear misunderstandings or mistaken interpretations increase. The students are also not developing the central academic skill of argumentation. The teacher is not aware of what the students are thinking, which could be more obvious in direct communication. The students' thoughts can remain their own to the end of the course, even until returning the learning diary. From the point of view of the continuity of the learning process it would be ideal if the teacher could, within resources, still arrange a web-based feedback discussion at the end of the course where the teacher would sum up the contributions of the study module, crystallize the core contents of the students' learning outputs and outline the possible future directions of the learning process. At the end of the study module every student got a grade and a verbal feedback, however, this was brief due to the teacher's limited time resources.

\section{Conclusions}

The keys for the success in the web-based teaching are the sufficient knowledge of the starting points of participants in the teaching, strong knowledge of contents and a creative attitude to the online possibilities and, on the other hand, the realization of restrictions. It is probably not worth aiming for the ultimate right way to implement web-based teaching, the development is a constant attempt to do better.

With the high-quality e-pedagogical planning, such as by pacing the teaching, and with the application tasks that have been meaningfully placed in the teaching material as well as with the low-threshold supervision, the teacher can facilitate the adult student's learning process. The constant reflection and development cycle are emphasized, also the starting points of the participants, e-pedagogical and adult pedagogical principles, such as flexibility and the independence of time and place need to be paid attention to. Also the teachers' cooperation, the reflection and envisioning the new promote the high quality and expanding use of web-based methods.

Technology is a tool and an enabler of studying the core contents. Attention should be directed at the contents instead of technical points and, in particular where adult students are concerned, to their earlier experiences, matters to be learned and their application value, for example, in working life where an increasingly high level of competence is required.

The utilization of new innovative online possibilities makes lifelong learning, participation in the adult education and the expanding of the own know-how possible which is positively reflected also in the context of work and in the society. In the future the multidimensional e-learning will be a growing trend - also in academic contexts as well as in other 
parts of the society, the learning experiences of the participants and the renewing needs and their conscious reflection are at the core of the continuous development.

\section{REFERENCES}

Beck, Ulrich, and Elizabeth Beck-Gernsheim. 2002. Individualization: Institutionalized Individualism and Its Social and Political Consequences. London: Sage Publications.

Billett, Stephen. 2001. Learning in the Workplace: Strategies for Effective Practice. Sydney: Allen \& Unwin.

Cervero, Ronald, M., and Arthur L. Wilson. 2001. "At the Heart of Practise. The Struggle for Knowledge and Power." In Power in Practise: Adult Education and the Struggle for Knowledge and Power, edited by Ronald M. Cervero, and Arthur L. Wilson, 1-20. San Fransisco: Jossey-Bass.

Dirkx, John, M. 2008. "The Meaning and Role of Emotions in Adult Learning.” New Directions for Adult and Continuing Education. Special Issue: Adult Learning and the Emotional Self, 120:7-18. doi: 10.1002/ace.311.

Donovan, Loretta, Tim Green, and Candice Mason. 2014.”Examing the $21^{\text {st }}$ Century Classroom: Developing an Innovation Configuration Map.” Journal of Educational Computing Research 50(2):161-78. doi: 10.2190/EC.50.2.a.

Hakala, Ismo, and Mikko Myllymäki. 2013.’Ubiquitous Learning Environment Based on Lecture Videos.” Paper presented at the $6^{\text {th }}$ International Conference of Education, Research and Innovation, Seville, Spain, November 18-20.

Hara, Noriko, and Rob Kling. 2000. "Student Distress in a Web-based Distance Education Course.” Information, Communication \& Society 3(4):557-79. doi: 10.1080 /13691180010002297.

Huang, Hsiu-Mei. 2002. "Toward Constructivism for Adult Learners in Online Learning Environments." British Journal of Educational Technology 33(1):27-37. doi: 10.1111/1467-8535.00236.

Hämäläinen, Raija, and Katja Vähäsantanen. 2011. ”Theoretical and Pedagogical Perspectives on Orchestrating Creativity and Collaborative Learning.” Educational Research Review 6: 169-84. doi: 10.1016/j.edurev.2011.08.001.

Isosomppi, Leena, and Minna Maunula. 2014.”Adult Students in Web-based Thesis Seminars Insights and Challenges for Supervision.” Paper presented at the Multidisciplinary Academic Conference on Education, Teaching and E-learning, Prague, Czech Republic, October 8-9.

Leonard, Diana, Rosamunde Becker, and Kelly Coate. 2005. "To Prove Myself at the Highest Level: The Benefits of Doctoral study.” Higher Education Research and Development 24(2):135-50. doi: 10.1080/07294360500062904.

Makkonen, Pekka. 2003. "Is Web-based Seminar an Effective Way of Learning in Adult Education?" Paper presented at the $36^{\text {th }}$ Hawaii International Conference on System Sciences. Waikoloa Village, Hawaii, January 6-9.

Maor, Dorit. 2003. "The Teacher's Role in Developing Interaction and Reflection in an Online Learning Community.” Educational Media International 40(1-2):127-37. doi: 10.1080/0952398032000092170.

Maunula, Minna. 2014a. ”Doctoral Students' Everyday Experiences in the Changing Contexts.” Paper presented at the $6^{\text {th }}$ International Conference on Education and New Learning Technologies, Barcelona, Spain, July 7-9.

Maunula, Minna. 2014b. "Perheellisen naistohtoriopiskelijan arki, elämänkulku ja tulevaisuusajattelu.” PhD diss., University of Jyväskylä. 
Molesworth, Mike, Elizabeth Nixon, and Richard Scullion. 2009. ”Having, Being and Higher Education: The Marketisation of the University and the Transformation of the Student into Consumer." Teaching in Higher Education 14(3):277-87. doi: 10.1080/13562510902898841.

Paavola, Sami, and Kai Hakkarainen. 2009. "From Meaning Making to Joint Construction of Knowledge Practices and Artefacts - A Trialogical Approach to CSCL.” Paper presented at the CSCL2009 Conference, Rhodes, Greece, June 8-13.

Patton, Michael, Q. 2002. Qualitative Research and Evaluation Methods. $3^{\text {rd }}$ edition. Thousand Oaks: Sage.

Persell, Caroline, H. 2004. "Using Focused Web-Based Discussions to Enhance Student Engagement And Deep Understanding.” Teaching Sociology 32:61-78. doi: 10.1177/0092055X0403200107.

Rubenson, Kjell, and Richard Desjardins. 2009. ”The Impact of Welfare State Regimes on Barriers to Participation in Adult Education. A Bounded Agency Model.” Adult Education Quarterly 59(3):187-207. doi: 10.1177/0741713609331548.

Selwyn, Neil, Stephen Gorard, and John Furlong. 2006. Adult Learning in the Digital Age. London: Routledge.

Southerton, Dale. 2011. ”Are We Running out of Time?” In Sociology of Personal Life, edited by Vanessa May, 121-33. London: Palgrave Macmillan.

Wallace, Raven, M. 2003. ”Online Learning in Higher Education: A Review of Research in Interactions among Teachers and Students.” Education, Communication \& Information 3(2):241-80. doi: 10.1080/14636310303143.

Wang, Qiyun. 2009. ”Designing a Web-based Constructivist Learning Environment.” Interactive Learning Environment 17(1):1-13. doi: 10.1080/10494820701424577.

Zembylas, Michalinos. 2008. "Adult Learners' Emotions in Online Learning.” Distance Education 29(1):71-87. doi: 10.1080/01587910802004852.

\section{ABOUT THE AUTHORS}

Isosomppi Leena: PhD (Education) works in University of Jyväskylä, Kokkola University Consortium Chydenius as a senior lecturer. Her interests relating to research focus on teachers' professional development, mentoring, adult pedagogics, inclusion and gender bias in education.

Maunula Minna: PhD (Education) works in University of Jyväskylä, Kokkola University Consortium Chydenius as a university teacher. Her interests relating to research focus on the wholenesses of adults' lifecourse, the significance of education in the global time and also on developing web-based and multiform adult education. 